AIP Applied Physics

\title{
Enhancement of optical absorption by modulation of the oxygen flow of TiO2 films deposited by reactive sputtering
}

André L. J. Pereira, Paulo N. Lisboa Filho, Javier Acuña, luri S. Brandt, André A. Pasa et al.

Citation: J. Appl. Phys. 111, 113513 (2012); doi: 10.1063/1.4724334

View online: http://dx.doi.org/10.1063/1.4724334

View Table of Contents: http://jap.aip.org/resource/1/JAPIAU/v111/i11

Published by the American Institute of Physics.

\section{Additional information on J. Appl. Phys.}

Journal Homepage: http://jap.aip.org/

Journal Information: http://jap.aip.org/about/about_the_journal

Top downloads: http://jap.aip.org/features/most_downloaded

Information for Authors: http://jap.aip.org/authors

\section{ADVERTISEMENT}

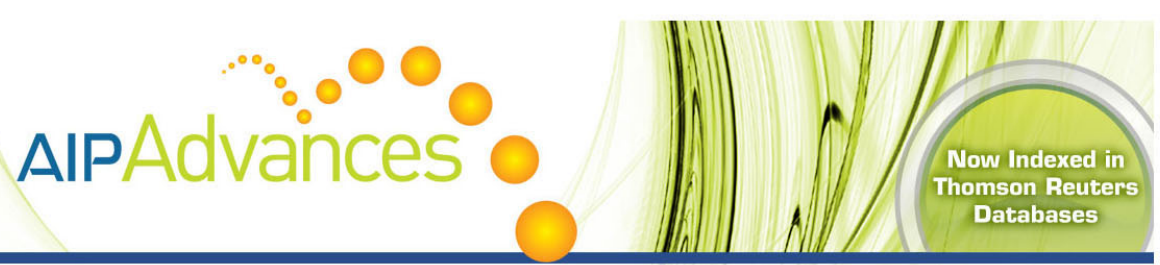

\section{Explore AIP's open access journal: • Rapid publication \\ - Article-level metrics \\ - Post-publication rating and commenting}




\title{
Enhancement of optical absorption by modulation of the oxygen flow of $\mathrm{TiO}_{2}$ films deposited by reactive sputtering
}

\author{
André L. J. Pereira, ${ }^{1,2}$ Paulo N. Lisboa Filho, ${ }^{1}$ Javier Acuña, ${ }^{3}$ luri S. Brandt, ${ }^{3}$ \\ André A. Pasa, ${ }^{3}$ Antonio R. Zanatta, ${ }^{4}$ Johnny Vilcarromero, ${ }^{5}$ Armando Beltrán, ${ }^{2}$ \\ and José H. Dias da Silva ${ }^{1, a)}$ \\ ${ }^{1}$ Universidade Estadual Paulista, UNESP, Bauru SP, Brazil \\ ${ }^{2}$ Universitat Jaume I, Castellón, Spain \\ ${ }^{3}$ Universidade Federal de Santa Catarina, UFSC, Florianópolis SC, Brazil \\ ${ }^{4}$ Universidade de São Paulo, USP, São Carlos SP, Brazil \\ ${ }^{5}$ Universidade Federal de São Carlos, UFSCar, Sorocaba SP, Brazil
}

(Received 7 March 2012; accepted 1 May 2012; published online 5 June 2012)

\begin{abstract}
Oxygen-deficient $\mathrm{TiO}_{2}$ films with enhanced visible and near-infrared optical absorption have been deposited by reactive sputtering using a planar diode radio frequency magnetron configuration. It is observed that the increase in the absorption coefficient is more effective when the $\mathrm{O}_{2}$ gas supply is periodically interrupted rather than by a decrease of the partial $\mathrm{O}_{2}$ gas pressure in the deposition plasma. The optical absorption coefficient at $1.5 \mathrm{eV}$ increases from about $1 \times 10^{2} \mathrm{~cm}^{-1}$ to more than $4 \times 10^{3} \mathrm{~cm}^{-1}$ as a result of the gas flow discontinuity. A red-shift of $\sim 0.24 \mathrm{eV}$ in the optical absorption edge is also observed. High resolution transmission electron microscopy with composition analysis shows that the films present a dense columnar morphology, with estimated mean column width of $40 \mathrm{~nm}$. Moreover, the interruptions of the $\mathrm{O}_{2}$ gas flow do not produce detectable variations in the film composition along its growing direction. X-ray diffraction and micro-Raman experiments indicate the presence of the $\mathrm{TiO}_{2}$ anatase, rutile, and brookite phases. The anatase phase is dominant, with a slight increment of the rutile and brookite phases in films deposited under discontinued $\mathrm{O}_{2}$ gas flow. The increase of optical absorption in the visible and near-infrared regions has been attributed to a high density of defects in the $\mathrm{TiO}_{2}$ films, which is consistent with density functional theory calculations that place oxygen-related vacancy states in the upper third of the optical bandgap. The electronic structure calculation results, along with the adopted deposition method and experimental data, have been used to propose a mechanism to explain the formation of the observed oxygen-related defects in $\mathrm{TiO}_{2}$ thin films. The observed increase in sub-bandgap absorption and the modeling of the corresponding changes in the electronic structure are potentially useful concerning the optimization of efficiency of the photocatalytic activity and the magnetic doping of $\mathrm{TiO}_{2}$ films. (C) 2012 American Institute of Physics.

[http://dx.doi.org/10.1063/1.4724334]
\end{abstract}

\section{INTRODUCTION}

The several existing and the potential new applications of $\mathrm{TiO}_{2}$ films in the fields of biocompatibility, photovoltaics, self-cleaning processes, non-toxic photocatalysis, and use in diluted magnetic oxides have driven intensive research in recent years. ${ }^{1-5}$ Indeed, the interest in increasing the optical absorption at energies corresponding to the visible and nearinfrared spectral ranges derives from the possibility to change the photocatalytic activity of this material from the ultraviolet to the visible and near infrared. ${ }^{1,2}$

For many applications, the presence of defects plays a fundamental role. In particular, the oxygen-related vacancies are among the most important, since they are believed to favor the interactions between the magnetic ions of transition metals (e.g., Mn or Co) in diluted magnetic oxides for spintronics devices ${ }^{4,5}$ and can be beneficial to the catalytic activ-

\footnotetext{
a) Author to whom correspondence should be addressed. Electronic mail: jhdsilva@fc.unesp.br.
}

ity by changing the charge state of the surfaces and enhancing the optical absorption. ${ }^{2}$

Concerning the use of $\mathrm{TiO}_{2}$ in photocatalysis, one of the aims is to induce optical absorption in the visible range. With this in mind, the effects of both intrinsic defects and extrinsic impurities have been tried through the insertion of $\mathrm{N}$, for example. ${ }^{1,3,6}$ It was observed that the depletion of the $\mathrm{O}_{2}$ by lowering the gas flow during deposition has little effect on the optical absorption of films produced by sputtering. The presence of defects in the $\mathrm{TiO}_{2}$ surface is important because they are expected to dominate the reactivity of the material, being of bold importance to catalysis. Therefore, there is a need for mechanisms that are able to control the defect creation in $\mathrm{TiO}_{2}$ in order to optimize its functionality. ${ }^{2,6}$

During plasma-assisted deposition processes, electron and ion bombardment are expected to influence the creation of defects such as vacancies and interstitials. ${ }^{7,8}$ In fact, the mechanisms involved in the deposition of $\mathrm{TiO}_{2}$ films by plasma-assisted methods are extremely complex and fundamental in determining the atomic displacements and oxygen diffusion in the surface of the growing films. ${ }^{7}$ 
Motivated by the above aspects, this report focuses on the deposition of $\mathrm{TiO}_{2}$ films by reactive sputtering using a $\mathrm{Ti}$ target in an $\mathrm{Ar}+\mathrm{O}_{2}$ atmosphere. Periodic interruptions of the $\mathrm{O}_{2}$ gas supply were adopted to produce controlled oxygen depletion in the films. The deposited films were characterized by optical and structural techniques and, together with density functional theory calculations, allowed the analysis of the effects of the oxygen depletion in the material. A mechanism for the defect creation due to the interrupted supply during the plasma deposition is proposed, and the possible implications concerning the applications are considered.

\section{EXPERIMENTAL}

The films have been deposited by radio frequency (RF) magnetron sputtering using a 75-mm-diameter metallic Ti target (99.999\% purity) in an $\mathrm{Ar}+\mathrm{O}_{2}$ atmosphere $(99.9999 \%$ purity). A Kurt J. Lesker sputtering chamber, model KJLSystem I, was used for the depositions. The system is equipped with a magnetron gun electrode mounted in a planar diode geometry and Advanced Energy RFX600 power source operating at $13.6 \mathrm{MHz}$. Resistive heating of the substrates has been used to produce samples at $450{ }^{\circ} \mathrm{C}$ and $600{ }^{\circ} \mathrm{C}$. The total pressure $\left(5.0 \times 10^{-3}\right.$ Torr $)$ in the system was measured using a capacitance manometer and controlled by a throttle valve. A
1000 l/s turbomolecular pump was employed. All deposition runs started only after a residual pressure smaller than $1.0 \times 10^{-6}$ Torr was achieved. A residual gas analyzer was used to check the system contamination: generally the more important contaminants are water vapor $(\sim 70 \%)$ and hydrogen $(\sim 10 \%)$, hydrocarbons being less than $5 \%$.

Silica glass $\left(\mathrm{a}-\mathrm{SiO}_{2}\right)$ and lanthanum aluminate $\left(\mathrm{LaAlO}_{3}\right)$ substrates were used simultaneously in the depositions. $\mathrm{Si}(100)$ substrates were also used in some cases. The deposition conditions, consisting of a set of constant and a set of variable parameters, are summarized in Table I. The sample reproducibility was tested by depositing samples in identical conditions and checking the structural and optical properties. The main checks in this group of samples were indicated by the different labels for the same conditions in Table I. The uncertainties indicated in the film thickness, deposition rate, static refractive index, and bandgap resulted from the optical calculations.

Electronic mass flow controllers (Edwards Vacuum) with 0.2 -sccm (standard cubic centimeters per minute) sensibility and $50-\mathrm{sccm}$ full scale were used to control the gas flow. The flow shutoff was attained by closing a manual valve and the mass flow controller, so no $\mathrm{O}_{2}$ flowed to the system, nevertheless a mixture of $\mathrm{Ar}$ and $\mathrm{O}_{2}$ is present on the $1.5-\mathrm{m}$, 6-mm-diameter line located between the valve and chamber

TABLE I. Deposition and optical characterization parameters of $\mathrm{TiO}_{2}$ films prepared by RF magnetron sputtering.

\section{Constant parameters}

Target-metallic Ti $(99.999 \%)$

RF power- $120 \mathrm{~W}$, reflected RF power-3 to $4 \mathrm{~W}$ depending on deposition

Geometry—planar diode, cylindrical symmetry, target diameter $75 \mathrm{~mm}$, target to substrate distance, $50 \mathrm{~mm}$

Total pressure- $5.0 \times 10^{-3}$ Torr

Substrate temperature $-450^{\circ} \mathrm{C}$, electrically grounded

Argon flux-40 sccm

Substrates-amorphous silica $\left(\mathrm{a}-\mathrm{SiO}_{2}\right)$, lanthanum aluminate $(\mathrm{LaAlO} 3)$, silicon $(\mathrm{Si}(100))^{\mathrm{a}}$

Buffer layer used in interrupted flux films- $60 \mathrm{~nm}$ thick, 18 min deposition, $0.2 \mathrm{sccm} \mathrm{O}_{2}$ flux

\begin{tabular}{|c|c|c|c|c|c|c|c|c|c|c|}
\hline \multicolumn{11}{|c|}{ Variable parameters } \\
\hline \multirow[b]{2}{*}{ Sample } & \multirow[b]{2}{*}{$\begin{array}{r}\mathrm{O}_{2} \text { flux } \\
(\mathrm{sccm})\end{array}$} & \multirow[b]{2}{*}{$\begin{array}{l}\mathrm{O}_{2} \text { flow } \\
\text { mode }\end{array}$} & \multicolumn{3}{|c|}{ Period characteristics } & \multirow[b]{2}{*}{$\begin{array}{l}\text { Total deposition } \\
\text { time (min) }\end{array}$} & \multirow[b]{2}{*}{$\begin{array}{c}\text { Film } \\
\text { thickness (nm) }\end{array}$} & \multirow[b]{2}{*}{$\begin{array}{l}\text { Deposition } \\
\text { rate }(\mathrm{A} / \mathrm{s})\end{array}$} & \multirow[b]{2}{*}{$\begin{array}{l}\text { Static refractive } \\
\text { index }\left(\mathrm{n}_{\mathrm{o}}\right)\end{array}$} & \multirow[b]{2}{*}{$\begin{array}{l}\text { Bandgap } \\
(\mathrm{eV})\end{array}$} \\
\hline & & & $\begin{array}{l}\text { Interruption } \\
\text { interval (s) }\end{array}$ & $\begin{array}{l}\text { Number of } \\
\text { interruptions }\end{array}$ & $\begin{array}{l}\text { Open flux } \\
\text { interval (s) }\end{array}$ & & & & & \\
\hline KL11 & 2.0 & Continuous & $\ldots$ & $\ldots$ & $\ldots$ & 180 & $402 \pm 10$ & $0.37 \pm 0.01$ & $2.33 \pm 0.01$ & $3.38 \pm 0.05$ \\
\hline KL16 & 6.0 & Continuous & $\ldots$ & $\ldots$ & $\ldots$ & 180 & $410 \pm 10$ & $0.38 \pm 0.01$ & $2.30 \pm 0.01$ & $3.35 \pm 0.05$ \\
\hline KL15 ) & 0.2 & Continuous & $\ldots$ & $\ldots$ & $\ldots$ & 180 & $618 \pm 50$ & $0.57 \pm 0.05$ & $2.11 \pm 0.01$ & $3.37 \pm 0.05$ \\
\hline \multicolumn{11}{|l|}{$\left.\begin{array}{l}\text { KL45 } \\
\text { KL33 }\end{array}\right\}$} \\
\hline KL20 & 0.2 & Interrupted & 10 & 20 & 540 & 180 & $538 \pm 20$ & $0.50 \pm 0.02$ & $2.29 \pm 0.02$ & $3.34 \pm 0.05$ \\
\hline $\left.\begin{array}{l}\text { KL21 } \\
\text { KL32 }\end{array}\right\}$ & 0.2 & Interrupted & 45 & 20 & 540 & 204 & $714 \pm 30$ & $0.58 \pm 0.03$ & $2.29 \pm 0.01$ & $3.17 \pm 0.05$ \\
\hline KL22 & 10.0 & Interrupted & 45 & 20 & 540 & 221 & $907 \pm 40$ & $0.68 \pm 0.04$ & $2.56 \pm 0.07$ & $3.14 \pm 0.05$ \\
\hline KL23 & 0.2 & Interrupted & 38 & 20 & 540 & 211 & $659 \pm 40$ & $0.52 \pm 0.04$ & $2.25 \pm 0.01$ & $3.38 \pm 0.05$ \\
\hline KL24 & 0.2 & Interrupted & 45 & 10 & 1080 & 205 & $643 \pm 30$ & $0.60 \pm 0.03$ & $2.30 \pm 0.01$ & $3.29 \pm 0.05$ \\
\hline KL25 & 0.2 & Interrupted & $\begin{array}{c}45 \mathrm{i} / 20 \mathrm{o} / 45 \mathrm{i} \\
\text { (double interruption layer) }\end{array}$ & 20 & 1080 & 213 & $677 \pm 50$ & $0.53 \pm 0.05$ & $2.33 \pm 0.01$ & $3.22 \pm 0.05$ \\
\hline KL27 & 0.2 & Interrupted & 140 & 1 & 6340 & 214 & $\ldots$ & $\ldots$ & $\ldots$ & $\ldots$ \\
\hline
\end{tabular}

${ }^{a}$ Samples KL32 and KL33 have been deposited also onto Si substrates using the same conditions as KL21 and KL15, in order to perform the transmission electron microscopy and x-ray diffraction experiments. Samples deposited using the same conditions with different labels were used also to check the reproducibility of the results. 
entrance. The argon flux was kept constant at $40 \mathrm{sccm}$ in all deposition runs. A clear change in the plasma emission color was observed exactly $40 \mathrm{~s}$ after shutting down the valve. The characteristic color of the $\mathrm{Ar}+\mathrm{O}_{2}$ was re-established instantly after the valve and mass flow were opened.

The atomic structure of the $\mathrm{TiO}_{2}$ films were characterized by $\mathrm{x}$-ray diffraction (XRD) using grazing incidence (GIXRD) and Bragg-Brentano geometries. To check the orientation texture, pole figures of selected diffraction planesrecorded by keeping the $\theta-2 \theta$ fixed and scanning over the hemisphere by variation of the angles of inclination $(\omega)$ and azimuth $(\psi)$-were also obtained. The x-ray diffraction experiments were performed in a Phillips model Xpert PRO MPD setup, with $\mathrm{Cu}$ electrode and diffracted beam monochromator. No background subtraction or pole alignment has been performed in the pole figures, so the results correspond to the bare measurements. Complementary structural information was obtained by high-resolution transmission electron microscopy (HRTEM), which also provided the composition of the films. The HRTEM experiments were performed using a JEOL (model JEM-2100) 200-kV microscope, equipped with a LaB6 electron gun. Energy-filtered images were recorded in low resolution in order to check the composition homogeneity of the samples. Films deposited onto $\operatorname{Si}(100)$ were used in the analysis in order to avoid charging effects.

Raman scattering measurements were carried out in a commercial micro-Raman setup (Renishaw RM2000) equipped with a 1200 -lines $/ \mathrm{mm}^{-1}$ diffraction grating and an optical microscope, rendering a spectral resolution of $\sim 2 \mathrm{~cm}^{-1}$ and a spatial resolution of $\sim 1 \mu \mathrm{m}^{2}$. The experiments were performed under the back-scattering geometry. The films were excited by the $632.8-\mathrm{nm}(1.96-\mathrm{eV})$ line of a $\mathrm{He}-\mathrm{Ne}$ laser, and no preferential polarization was adopted.

The regular optical transmittance spectra were recorded in a Shimadzu UVmini-1240. The integrated transmittance, reflectance, and forward scattered intensities were measured using a Perkin-Elmer Lambda 1050, with a $150-\mathrm{mm}$ integrating sphere attachment (Labsphere 150).

When measuring the integrated transmittance, integrated forward scattering, and total reflectance, it was necessary to use a blocking beam holder, since the beam produced by the equipment is bigger than the sample dimensions. Even though the appropriate zero- $100 \%$ correction procedure was performed prior to the measurements, some influence of the holder was noticed on the spectrum of the (forward) light scattering.

The absorption coefficients were determined from the optical transmittance spectra of the samples using the Cisneros' method ${ }^{9}$ with the help of a specially developed computational routine. The complete expressions derived for homogenous thin film with parallel interfaces onto a thick substrate were used with no approximations. The method is based on the exponential dependence of the transmittance on the absorption coefficient in an iterative procedure.

The use of expressions for homogeneous thin films in the present absorption coefficient calculations is allowed by the fact that the estimated sizes of the crystallites are much smaller than the wavelengths of the spectral range used. Fur- ther, the differences between the optical constants of the $\mathrm{TiO}_{2}$ anatase, rutile, and brookite phases are not large, ${ }^{10,11}$ so the use of an effective (predominantly anatase) medium does not introduce significant errors.

Considering that the anatase is the dominant phase in the analyzed films (as will be shown in Sec. III) and considering that anatase gives rise to an indirect bandgap material, ${ }^{10,11}$ the usual relationship

$$
\alpha=A\left(h v-E_{g}\right)^{2},
$$

where $\alpha$ is the absorption coefficient (in $\mathrm{cm}^{-1}$ ), $h v$ is the photon energy, and $E_{g}$ is the bandgap energy (in $\mathrm{eV}$ ), was employed in a plot of $\sqrt{\alpha}$ versus $h v$ in order to determine the bandgap of the $\mathrm{TiO}_{2}$ films. ${ }^{10-13}$ The range of $\sqrt{\alpha}$ used in the linear fit of Eq. (1) was $100 \mathrm{~cm}^{-1 / 2}$ to $300 \mathrm{~cm}^{-1 / 2}$, while in single crystals, the range is generally below $100 \mathrm{~cm}^{-1 / 2} \cdot{ }^{12,13}$ This is due to the much greater thickness of the crystalline specimens used.

For a better interpretation of the influence of oxygen vacancies in the electronic structure of $\mathrm{TiO}_{2}$, density functional theory (DFT) calculations were carried out using the CRYSTAL09 program package. ${ }^{14}$ A $2 \times 2 \times 2$ anatase supercell with 48 atoms ${ }^{15}$ having $I 4_{1} /$ amd symmetry and Becke's threeparameter hybrid non-local exchange functional ${ }^{16}$ combined with the Lee-Yang-Parr gradient-corrected correlation functional, B3LYP (Ref. 17) were used in the calculations. The O atoms were represented by the $6-31 \mathrm{G}(\mathrm{d} 1)$ Gaussian basis set, available at the Crystal website. ${ }^{14}$ For the titanium atom, the 6-31G basis set developed by Rassolov et al. ${ }^{18}$ was selected, as in a previous work. ${ }^{19}$ In order to improve the accuracy of our results, we applied the empirical correction scheme for energy in periodic systems that considers a functional density dependent global scaling factor and the long-range dispersion contributions proposed by Grimme ${ }^{20}$ and implemented by Bucko et al. ${ }^{21}$ The basic strategy in the development is to restrict the density functional description to shorter electron correlation lengths scales and to describe situations with medium to large interatomic distances by damped $C_{6}^{i j} \cdot R_{i j}^{-6}$ terms, where $C_{6}^{i j}$ denotes the dispersion coefficient for atom pair $i j$, and $R_{i j}^{-6}$ is the corresponding interatomic distance. ${ }^{20}$

\section{RESULTS}

Two sets of $\mathrm{TiO}_{2}$ films were considered in the present investigation. The first set corresponds to films produced using different continuous $\mathrm{O}_{2} / \mathrm{Ar}$ flow ratios, and the second was related to films produced by periodically interrupting the $\mathrm{O}_{2}$ flow during depositions. The deposition conditions are summarized in Table I. It is worth noting that the starting point for the set of interrupted flow samples was the condition of the lowest controllable $\mathrm{O}_{2}$ flux of the first set, corresponding to an $\mathrm{O}_{2} / \mathrm{Ar}$ ratio of 0.005 . Table I also contains the deposition rates and optical constants, retrieved from the optical experiments.

Transmission electron microscopy images of films deposited on $\mathrm{Si}(100)$ substrates are shown in Fig. 1. Figures 1(a) and 1(b) show that in both flow regimes, the samples display columnar morphology with similar characteristics. The columns are tightly fitted and present estimated average 


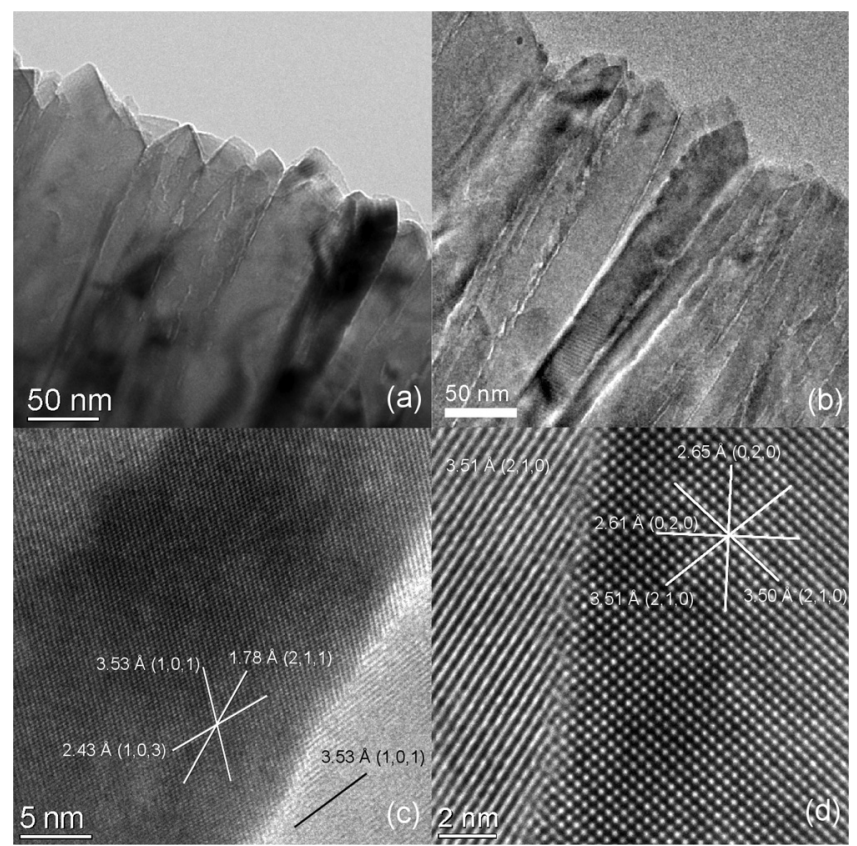

FIG. 1. Transmission electron microscopy of films deposited onto Si(100) substrates using different $\mathrm{O}_{2}$ gas flow conditions. (a) Interrupted $\mathrm{O}_{2}$ flow sample (KL32), showing the film-air interface. The columnar morphology of the film is apparent from the figure. (b) Continuous flow film (KL33) in which the columnar morphology is also clear. Some striped aspect regions noted in the figure are attributed to Moiré patterns, related to stress effects in the columns. (c) High resolution TEM of an interface between columns in interrupted flow sample (KL32). (d) Interface region between columns of a continuous flow sample (KL33).

width of $40 \mathrm{~nm}$. Figures 1(c) and 1(d) are high-resolution images showing column interfaces of interrupted and continuous flow samples, respectively. The misfit between atomic layers of the neighbor columns produces a defective region in the interface that can be seen in both situations. At the film/Si substrate interfaces, the HRTEM images support the presence of a native amorphous silicon oxide layer, $\sim 2 \mathrm{~nm}$ thick (not shown).

The XRD results, including the GIXRD, and pole figures of selected peaks are presented in Figs. 2 and 3, respectively. The diffraction data revealed that the anatase (tetragonal $\mathrm{I}_{4}$ /amd, ICSD\#154602), rutile (tetragonal $\mathrm{P}_{2} /$ mnm, ICSD\#898304), and brookite (ortorrombic Pbca, ICSD\#154605) phases coexist in the produced films, anatase being the predominant phase. The HRTEM electron diffraction and corresponding distances between planes are also compatible with the presence of these three phases.

The x-ray diffractogram shown in Fig. 2(a) corresponds to $\mathrm{TiO}_{2}$ films deposited onto silicon substrate using low $\mathrm{O}_{2}$ flux (sample KL33, Table I). The use of increased $\mathrm{O}_{2}$ flows produced no important changes on the X-ray diffractograms. Only a slight increase of the rutile $\{110\}$ peak is worth mentioning when the $\mathrm{O}_{2} / \mathrm{Ar}$ ratio is increased to 0.15 . Figure 2(b) displays the $\mathrm{x}$-ray diffractogram corresponding to an interrupted flow sample (KL32). With the aim to produce oxygendeficient films, the lowest proportion of oxygen in the deposition gas $\left(\mathrm{O}_{2} / \mathrm{Ar}=0.2 \mathrm{sccm} / 40.0 \mathrm{sccm}=0.005\right)$ was used to deposit the films with interrupted oxygen flow. By comparing Figs. 2(a) and 2(b), it can be noticed that the x-ray
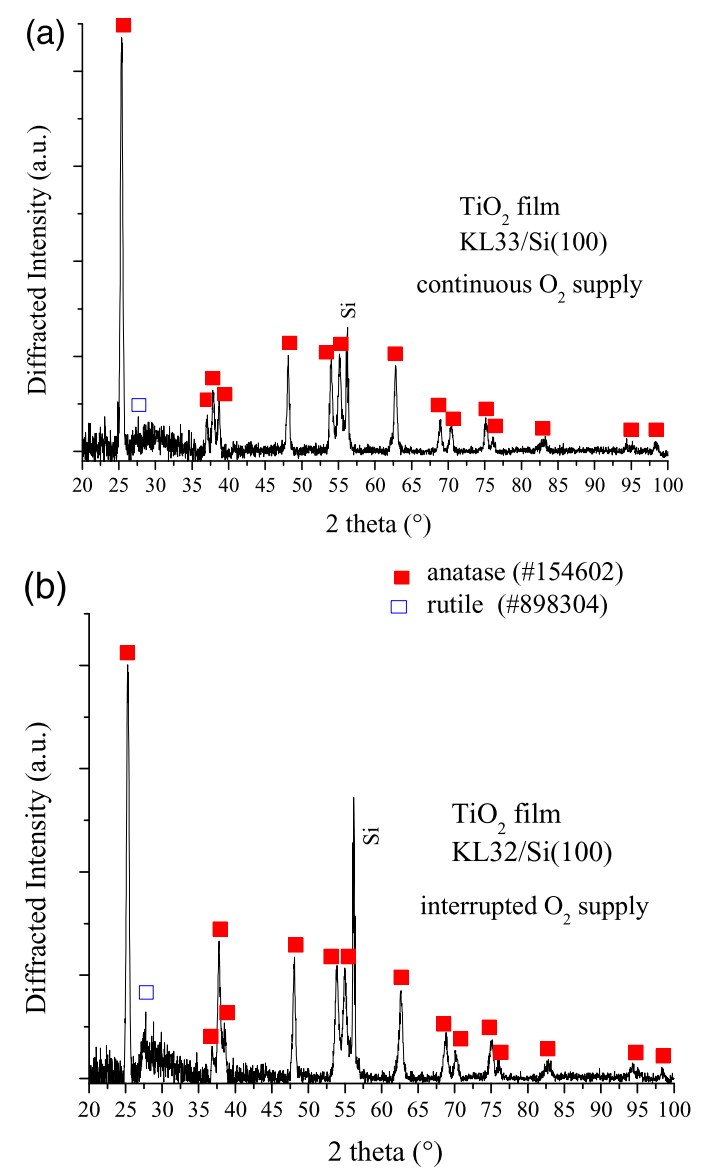

FIG. 2. Grazing incidence $\mathrm{x}$-ray diffraction of $\mathrm{TiO}_{2}$ films deposited by reactive sputtering, using $\mathrm{Ar}+\mathrm{O}_{2}$ gas supply and $\mathrm{Si}$ (100) substrate. (a) Sample deposited using continuous $\mathrm{O}_{2}$ supply (KL33). (b) Sample with the $\mathrm{O}_{2}$ supply interrupted by $45 \mathrm{~s}, 20$ times during the deposition (KL32). The diffraction peak at $2 \theta=56.2^{\circ}$ is attributed to the Si substrate.

diffraction patterns are similar, indicating that the structures of the films were not changed significantly with the $\mathrm{O}_{2}$ gas flow interruption. The only significant difference is the change in the relative intensities of the peaks at $2 \theta$ of $36.9^{\circ}, 37.8^{\circ}$, and $38.6^{\circ}$ corresponding to the anatase (103), (004), and (112) planes, respectively. It is worth mentioning that on sample KL32, deposited onto silica glass substrate, the peak associated to rutile at $27.7^{\circ}$ presents nearly the same intensity as the anatase peak at $25.2^{\circ}$, indicating that considerable differences in texture and structure can be related to the substrates. No peaks related to pure metallic Ti could be detected, in contrast to metallic test films deposited with no oxygen in the chamber, where the peaks were clear.

The lack of the peak at $2 \theta=30.8^{\circ}$ in the x-ray diffractogram, where a strong peak corresponding to the (111) $\mathrm{TiO}_{2}$ brookite (orthorhombic Pbca) is expected, and the fact that the several weak peaks attributed to the brookite in the $30^{\circ}-80^{\circ}$ range could not be identified in the diffractograms indicate that this phase presents a small fraction.

The pole figures corresponding to the anatase $\{101\}$, rutile $\{110\}$, and brookite $\{211\}$ planes were measured on samples deposited onto amorphous silica (Fig. 3). The observed patterns are diffuse, but texture effects can still be noticed as is frequently observed in sputtering deposited polycrystalline films. ${ }^{8,22}$ The brookite peaks have not being 
found in grazing angle or Bragg-Brentano diffractograms, but the $\{211\}$ pole figures indicate that this phase is present in both continuous and interrupted $\mathrm{O}_{2}$ supply films. It can be seen that the poles of the analyzed planes are more likely to be found in the $40^{\circ}-60^{\circ}$ range with the sample normal. Some patterns compatible with mosaic arrangement of crystallites are observed in the rutile $\{110\}$ and brookite $\{211\}$, while the distribution of the anatase $\{101\}$ presents itself with almost random azimuth angles. No significant change in the phase distribution and/or texture has been observed in association with the flux interruptions, as samples KL32 (interrupted) and KL33 (continuous) display similar pole figures.

In addition to the x-ray and electron microscopy analysis, the atomic structure and lattice vibrations of the $\mathrm{TiO}_{2}$ films were probed using micro-Raman scattering experiments. Figure 4 displays results of films deposited onto a$\mathrm{SiO}_{2}$ substrates. The frequencies and corresponding modes associated with the lattice vibrations of the anatase phase are $141 \mathrm{~cm}^{-1}\left(\mathrm{E}_{\mathrm{g}}\right), 195 \mathrm{~cm}^{-1}\left(\mathrm{E}_{\mathrm{g}}\right), 395 \mathrm{~cm}^{-1}\left(\mathrm{~B}_{1 \mathrm{~g}}\right), 514 \mathrm{~cm}^{-1}$ $\left(\mathrm{A}_{1 \mathrm{~g}}\right), 523 \mathrm{~cm}^{-1}\left(\mathrm{~B}_{1 \mathrm{~g}}\right)$, and $636 \mathrm{~cm}^{-1}\left(\mathrm{E}_{\mathrm{g}}\right)$. The peaks at $442 \mathrm{~cm}^{-1}\left(\mathrm{E}_{\mathrm{g}}\right)$ and $612 \mathrm{~cm}^{-1}\left(\mathrm{~A}_{1 \mathrm{~g}}\right)$ are attributed to the rutile. $^{23-25}$ The two weak peaks observed at $247 \mathrm{~cm}^{-1}$ and $319 \mathrm{~cm}^{-1}$ in Fig. 4 can be associated with the $A_{g}$ and $B_{1 g}$ modes of the brookite phase. ${ }^{24,26,27}$ Using the recorded spectra and the known vibration frequencies, one can infer the modifications produced by the different interruption intervals: the KL21(45s/20x) sample presents more important contributions of brookite and rutile, as compared to samples KL20(10s/20x) and K24(45s/10x), in which the flux interruptions were smaller.

The relative intensities and line shapes of the Raman spectra also significantly changed with the kind of substrate used. The spectra of films deposited onto $\mathrm{LaAlO}_{3}$ (not shown) displayed only small changes among the different films with interrupted flux: the anatase phase largely dominated the spectra of all films, while in Fig. 4, the spectra indicate that the contributions of rutile and brookite were noticeable in the sample more affected by the flux interruption (KL21). This indicates that the atomic structure of the films and the relation between the fractions of anatase, rutile, and brookite phases are influenced by the $\mathrm{O}_{2}$ gas flow interruption and also by the nature of the substrates used.

The optical transmittance, reflectance, and scattered intensities were measured to search for the sample optical characteristics (Fig. 5). The transmittance results of films deposited interrupting the $\mathrm{O}_{2}$ flow are displayed in Fig. 5(a).


KL33, Anatase (101), 25.3

KL32, Brookite (211), 30.8
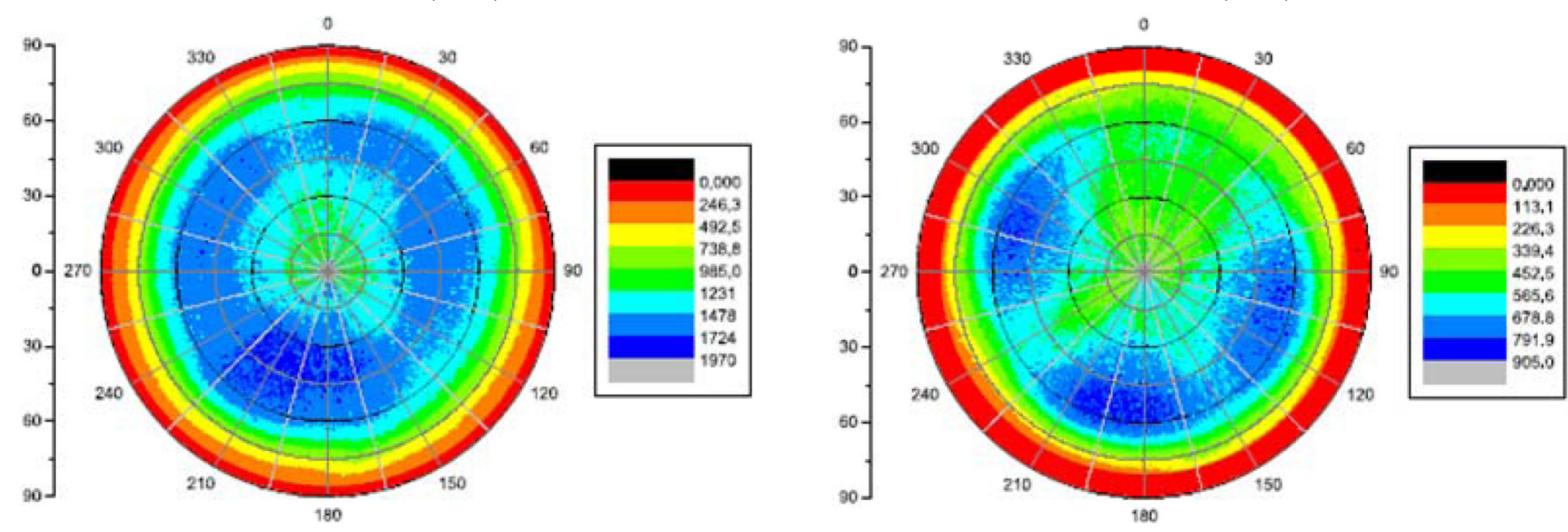

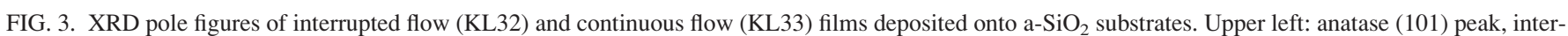
rupted flow sample (KL32). Lower left: anatase (101) peak, continuous flow sample (KL33). Upper right: rutile (110) interrupted flow sample (KL32). Lower right: brookite (211), interrupted flux sample. The data correspond to the bare measurements and are not background corrected. 


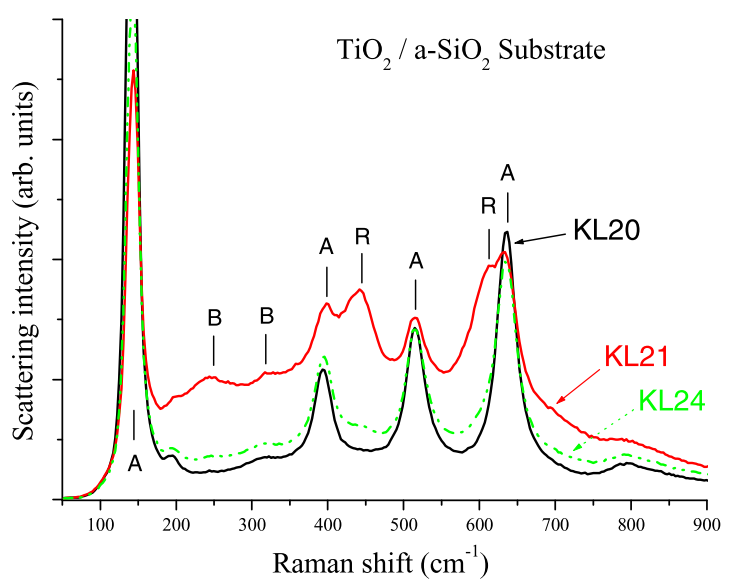

FIG. 4. Raman scattering spectra of samples deposited under different $\mathrm{O}_{2}$ flow conditions: black-sample KL20 with interruption of $\mathrm{O}_{2}$ supply for 10 s, 20 times; green-sample KL14, with 45 s, 10 interruptions; red-sample KL21, 45 s, 20 interruptions. The films are deposited onto a-SiO ${ }_{2}$ substrates.

The interference fringes show up at wavelengths bigger than $400 \mathrm{~nm}$, and the absorption edge drops the transmittances to zero below $350 \mathrm{~nm}$. The regularity of the interference fringes in the low absorption region of the produced films is compatible with the good optical homogeneity of the films.

The transmittance spectra can be grouped into those in which the maxima occur very close to the substrate and are associated with low visible-infrared absorption, and those which present decreased mean transmittance and absorption edges slightly red shifted (Fig. 5(a)). Samples KL20 and KL23 (green and blue curves, respectively) are associated with low visible-infrared absorption, being representative of the first group. These samples correspond to $\mathrm{O}_{2}$ interruptions smaller than $40 \mathrm{~s}$, while the others displayed in the figure correspond to flow interruptions of $45 \mathrm{~s}$ and $140 \mathrm{~s}$ (cyan, KL27).

The films deposited using continuous $\mathrm{O}_{2}$ gas flow (KL16/11/15/45) displayed characteristics similar to those grown using small interruption times. Samples corresponding to the minimum continuous attainable flux ratio $(0.2$ $\mathrm{sccm} / 40 \mathrm{sccm}$, KL15/45/33, Table I) present only a small decrease in the transmittance maxima (Fig. 5(a)).

In order to check if the observed attenuation of transmittances in interrupted flow samples was due to absorption or scattering, the integrated transmittance (straight + scattered) and the integrated forward scattered intensity of representative samples were measured. Fig. 5(b) displays the integrated transmittances of a continuous flow sample (blue curve, KL45) and of an interrupted flux sample (red, KL32). This figure also displays the respective integrated forward scattered intensities: the cyan curve corresponds to the continuous flux (KL45), while the orange curve corresponds to the interrupted flux sample (KL32).

In Fig. 5(c), the measured integrated percent transmittance (T) and reflectance (R) of an interrupted flux sample (KL32) are presented as well as the calculated values of sum $(\mathrm{R}+\mathrm{T})$ and of the percent absorbed intensity, $A=100-(R+T)$. It can be seen that the mean value of A presents a broad maximum at about $800 \mathrm{~nm}$.

The calculated values of the absorption coefficient of the films are plotted in Fig. 6. Samples having continuously


FIG. 5. Spectrophotometric characterization results. (a) Transmittance of interrupted flux films deposited under different conditions. (b) Total transmittances of different samples, measured by integrating the scattered plus straightly transmitted radiation with the help of an integrating sphere setup (PerkinElmer Labsphere 150). The spectrum of a silica glass slab (substrate) is included as reference. (c) Measured total transmittance (T) and total reflectance $(\mathrm{R})$, obtained by the use of an integrating sphere setup. The calculated $\mathrm{R}+\mathrm{T}$ curve and absorbed energy $(\mathrm{A}=100-(\mathrm{R}+\mathrm{T}))$, and the transmittance of the setup with no sample $(100 \% \mathrm{~T})$ are also shown.

decreasing absorption tails (KL15/16/20) were deposited using continuous $\mathrm{O}_{2}$ supply or interruption intervals shorten than $40 \mathrm{~s}$ (KL20).

In the higher photon energies of Fig. 6, an approximately linear behavior of $\log (\alpha)$ is present, defining the fundamental absorption edge of the different samples. The absorption edges of continuous supply films occur at higher energies and presents slightly steeper slopes as compared to the interrupted supply samples. As a result, a shift of $0.23 \mathrm{eV}$ to lower energies due to the flux interruptions is noticed.

In contrast to the relative similarity of the high absorption range, the low absorption displays remarkably different 


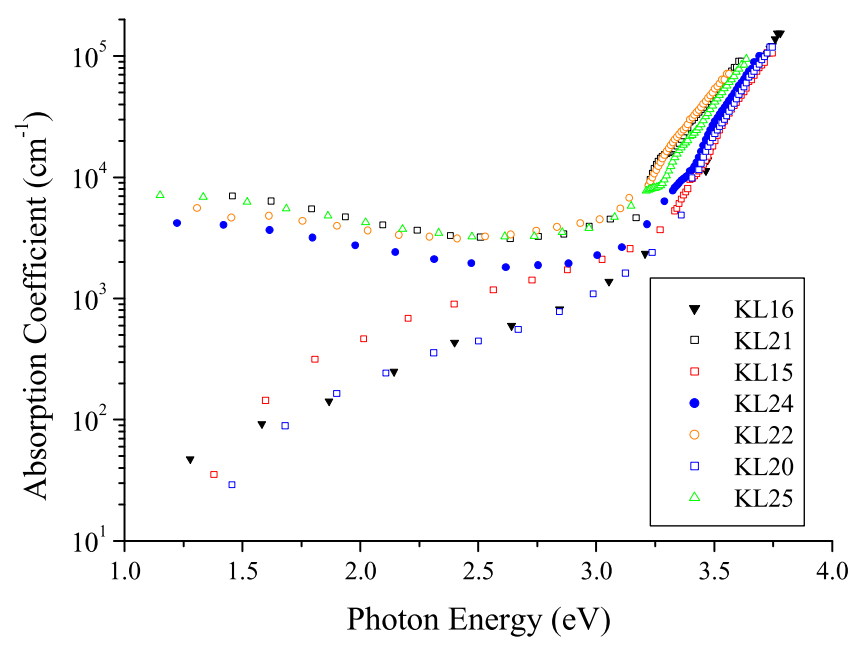

FIG. 6. Optical absorption coefficients of $\mathrm{TiO}_{2}$ films deposited under different conditions (specified in Table I).

behavior: in samples in which the $\mathrm{O}_{2}$ flow was interrupted for intervals longer than $45 \mathrm{~s}$, the sub-bandgap absorption was bigger. Under these conditions, the absorption coefficient presented a plateau of almost constant absorption at about $4 \times 10^{3} \mathrm{~cm}^{-1}$ in the $2.0-3.0 \mathrm{eV}$ range and presented a slight increase at lower energies (2.0-1.2 eV), while the absorption of the continuous flow samples dropped to a few hundred $\mathrm{cm}^{-1}$.

Using the calculated absorption coefficient data of Fig. 6 to plot $\sqrt{\alpha}$ versus $h v$ curves, that is, assuming indirect bandgaps of the phases involved, ${ }^{12,13}$ allows the determination of bandgaps in the $3.14-3.38 \mathrm{eV}$ range when considering the complete set of samples. The corresponding $\mathrm{E}_{\mathrm{g}}$ values for the different deposition conditions are shown in Table I.

Density functional calculations were performed using the CRYSTAL09 program package ${ }^{14}$ to investigate the effects of the oxygen vacancies on the electronic structure of anatase $\mathrm{TiO}_{2}$ crystals. The calculations have been performed using single and double oxygen vacancy configurations in an anatase $2 \times 2 \times 2$ supercell with 48 atoms. The supercell used in the calculations of single and double vacancies is show in Figs. 7(a) and 7(b), while the resulting density of states (DOS) is displayed in Figs. 8(a) and 8(b), respectively. The DOS peaks of the localized defect states in the bandgap are located around $1 \mathrm{eV}$ below the bottom of the conduction band.

\section{DISCUSSION}

Some aspects of the compact columnar morphology presented by the $\mathrm{TiO}_{2}$ films can be related to peculiar details of the sputtering deposition, such as typical energy and energetic distribution of depositing particles. ${ }^{7,8,28,29}$ A significant amount of the precursors reaching the surface of the forming film present an energy distribution resulting from the plasma processes, so their mean energies are considerably higher than the thermal energy provided by the substrate heating. ${ }^{7,28}$ With the adopted deposition parameters, the mean free path in the plasma is expected to be of the order of the target to substrate distance, so the sputtered atoms from the target should arrive at the substrate with low energy losses as compared to the just ejected ones, typically in the $1-40 \mathrm{eV}$ range. $^{7,29}$ Also, the reflected species (essentially argon and oxygen), which emerge from collisions with the target energies of the order of $\sim 100 \mathrm{eV}$, can hit the surface of the growing film, producing atomic surface scattering, sub-surface damage, and even some sputtering of the film. Additionally, in the planar diode configuration used, the flow of the species arriving from the target is rather directional, with incidence angles close to the substrate surface normal, favoring the columnar growth. ${ }^{8}$

Taking into account the energetic distribution of the plasma constituents and the moderate substrate temperature used $\left(450^{\circ} \mathrm{C}\right)$, the film precursors are expected to present surface diffusion lengths comparable to the observed column widths. In fact, the column width in this case is expected to be influenced essentially by atomic impact with a relatively small dependence of the substrate temperature. . $^{7,28}$

If on one hand the energy distribution details and directional deposition strongly influence the columnar morphology of the films, then on the other hand the deposition temperature is expected to have considerable influence on their crystallite structure. The slow deposition rate and the adopted substrate temperature $\left(450^{\circ} \mathrm{C}\right)$ are supposed to be responsible for a partial anneal of the produced defects and for some oxygen diffusion during growth. The predominantly anatase phase of the films is compatible with this relatively low substrate temperature. In a recent review of the deposition characteristics related to the magnetron sputtering deposition of $\mathrm{TiO}_{2}$ films, Mráz and Schneider ${ }^{7}$ clearly observed that the phase formation is controlled by the energy

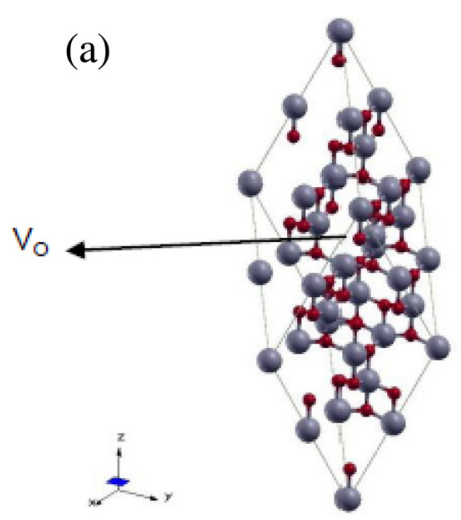

(b)

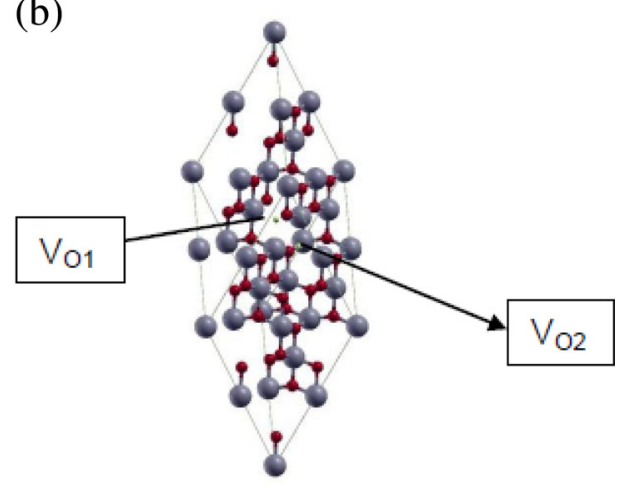

FIG. 7. Calculation supercell structure of anatase $\mathrm{TiO}_{2}$. (a) Single oxygen vacancy. (b) Double oxygen vacancy. 
(a)

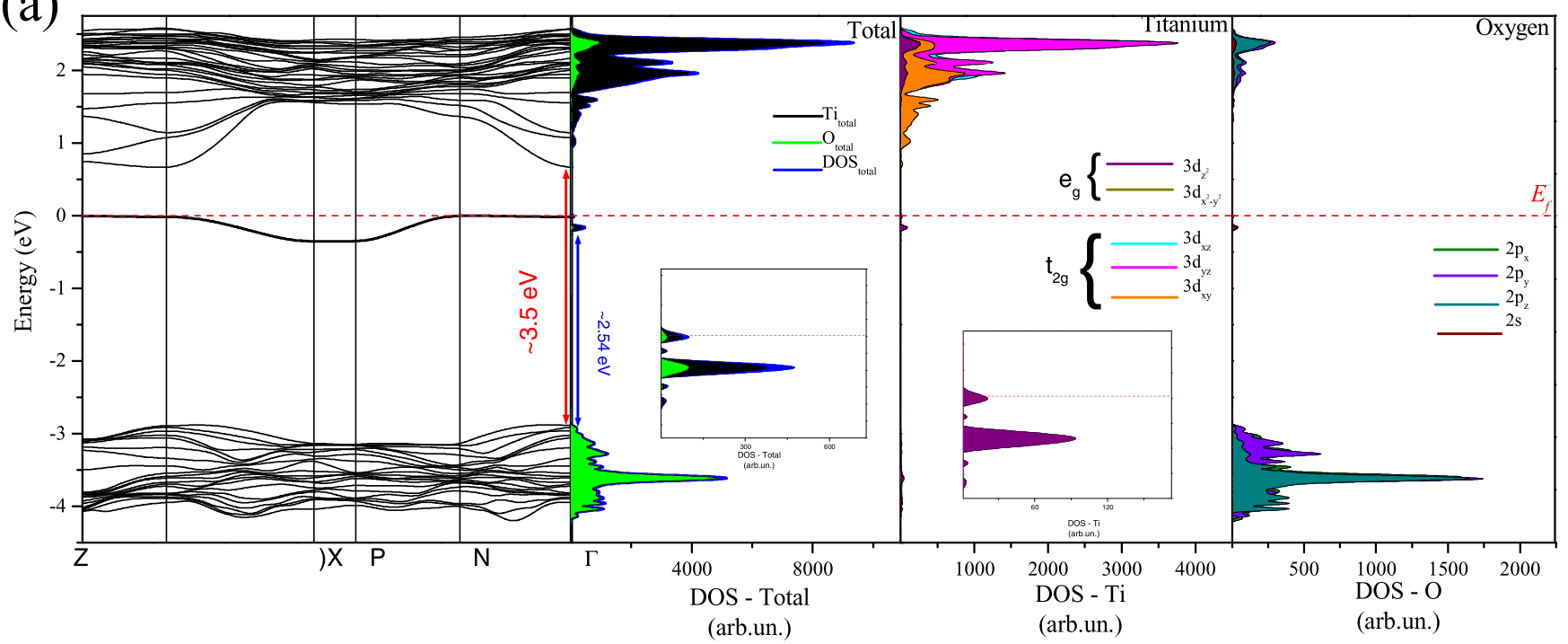

(b)

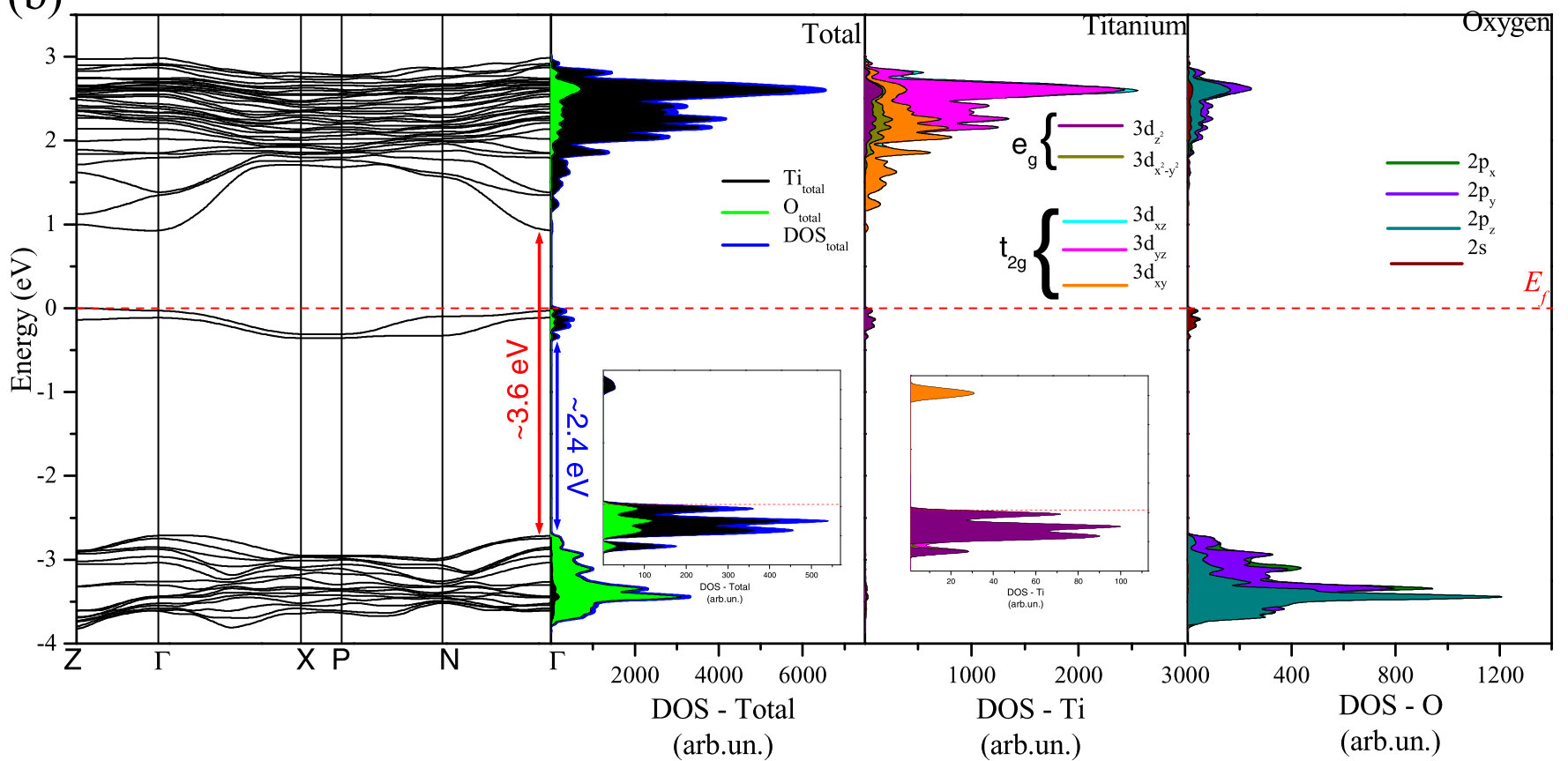

FIG. 8. Density of electronic states calculated using the CRYSTAL09 program. (a) Single vacancy per supercell. (b) Two vacancies per supercell. The insets correspond to the enlargement of DOS near the Fermi energy, which is represented by the horizontal dotted red line. The observed energies of the states in the gap due to oxygen vacancies are approximately in the $0.6-1.2 \mathrm{eV}$ range of energies below the conduction bands and are occupied states, so the corresponding energy values are in good agreement with the transmittance and absorption spectra.

of the particles reaching the substrate: the anatase dominates at lower energies, the rutile dominates at higher energies, and the intermediate energy is compatible with a mixture of these two phases. Even though the brookite phase is not mentioned and the substrates are not intentionally heated in the review of Mráz and Schneider, ${ }^{7}$ the depicted scenario provides a good explanation for the observed phase mixture. In other words, the deposition power $\left(3 \mathrm{~W} / \mathrm{cm}^{2}\right)$ is relatively low and compatible with the anatase predomination, but the small product pressure by distance $(\mathrm{pd}=33 \mathrm{~Pa} \times \mathrm{mm})$ causes small energy losses of the impinging species, allowing the formation of the rutile phase as well.

In spite of the good agreement concerning the energetics of the incident particles and the development of different phases, the substrate temperature also deserves special attention. Test samples deposited at $600^{\circ} \mathrm{C}$ (keeping all the other conditions constant) presented higher fractions of the rutile phase, in agreement with the literature reports focusing this parameter on sputter-deposited samples. ${ }^{30}$ There is a clear indication that both the kinetics of the impinging species and the thermal processes provided by the substrate play important roles concerning the morphology and structure of the films.

Still concerning the film deposition process, it is worth noting that despite the low $\mathrm{O}_{2} / \mathrm{Ar}$ ratio (0.005), interruptions of the $\mathrm{O}_{2}$ flow for short periods caused no important increase in the sub-bandgap absorption. Examples are samples KL20 and KL23 of Fig. 5(a). Also, the samples in which the optical 
absorption was significantly affected by the longer oxygen supply interruptions (45 s, 20 times) present no evidence for composition modulation in the transmission electron microscopy (including energy filtered images of both $\mathrm{Ti}$ and $\mathrm{O}$ ). At this point, it is interesting to mention the detailed study of the concentration of ionized $\mathrm{O}, \mathrm{O}_{2}$, and Ar of Okimura and Shibata: ${ }^{29}$ a remarkable dependence of these species on the partial pressure and on the $\mathrm{O}_{2}$ flow rate occurs, indicating that deposition conditions can change in a very complex way, especially on shutdown and restoring transients of the $\mathrm{O}_{2}$ flow.

The absence of clear Ti layers is consistent with the presence, in the deposition chamber, of reactive oxygen (electrically activated by the plasma) even after the interruption of the $\mathrm{O}_{2}$ supply. Such a presence of oxygen is mainly related to three factors:

(i) The RF plasma activates the $\mathrm{O}_{2}$, producing $\mathrm{O}_{2}^{*}, \mathrm{O}_{2}^{+}$, and free $\mathrm{O}$ in the chamber. The partial pressure of these highly reactive oxygen species is expected to be comparatively higher than that which is present in thermally activated processes at similar temperature and partial pressure. This occurs because the efficiency to produce activated species in the plasma is higher than that of thermal processes due to the higher energy of the charged species present.

(ii) When interrupting the $\mathrm{O}_{2}$ gas flow, a time delay of $40 \mathrm{~s}$ for a change in the plasma color is observed. This change is attributed to a modification in the plasma composition, from a mixture of $\mathrm{O}_{2}$ and Ar, to pure Ar. It is assumed, therefore, that the effective absence of oxygen in the chamber corresponds to this delay time, and consequently the effective period of sputtering of the target with the oxygen-depleted condition is only of the order of $5 \mathrm{~s}$ per interruption, which would result in the deposition of a few atomic layers.

(iii) In spite of the oxygen depletion in the plasma, the target surface is expected to be "contaminated" by this element due to the diffusion and reaction with the oxygen previously present in the plasma. Actually, because of the $\mathrm{Ti}-\mathrm{O}$ bond energy and deposition conditions, it is expected that the sputtering with pure argon will take some time to completely remove the oxygen from the Ti target.

In addition to the preceding arguments, when the $\mathrm{O}_{2}$ is restored it can react with the freshly deposited Ti-rich thin layer. This is favored by the enhanced energy of the plasma species: as the mean free path in the plasma for the used deposition conditions is of the order of the target to substrate distance, even oxygen atoms reflected from the collision with the target can reach the surface of the growing film. In the highest portion of the energy distribution, the oxygen resulting from nearly elastic collisions can have energies of the order of the bias voltage $(\sim 200 \mathrm{eV})$. The whole mechanism is assisted by a low deposition rate $(\sim 0.5 \AA / s)$.

The structural analysis shows that the predominant phase of the films grown with continuous $\mathrm{O}_{2}$ flow is the anatase, as indicated by the x-ray diffractograms and by the pole diagrams (Fig. 3). In the film grown with interruption of the
$\mathrm{O}_{2}$ flow, the XRD (Fig. 2) shows a mix between anatase and rutile. This phase mix is also evident in the Raman measurements. The Raman spectra of samples deposited with 45-s interruptions exhibits both rutile- and brookite-related peaks, even though the contributions related to anatase still dominate the spectra. However, the pole figures of films deposited with interruption of $\mathrm{O}_{2}$ supply display essentially the same characteristics of the low continuous-supply $\mathrm{O}_{2}$ film, indicating that the rutile phase as well as the brookite phase were already present in the continuous film.

The x-ray diffractograms and pole figures of films deposited onto silicon substrates with interruption of $\mathrm{O}_{2}$ gas display essentially the same characteristics of the low continuoussupply $\mathrm{O}_{2}$ films. On films deposited onto silica there is a tendency to increase the rutile phase in the interrupted flux films (also observed in the Raman scattering experiments): the Raman scattering spectra show a favoring of rutile- and brookite-related peaks, even though the peaks related to the anatase still dominate the spectra. So in a gross way, the films are still dominated by the anatase phase with inclusions of rutile and brookite. This reversal of the tendency to favor anatase in the interrupted flux can be related to a different growth regime caused by the Ti-rich layers deposited during the interruption of the $\mathrm{O}_{2}$ supply. The polymorphic nature of the material is corroborated by HRTEM, with no clear distinction between the results for samples obtained by the use of interrupted or continuous gas supply parameters.

The change in the microstructure after the supply interruption detected by the Raman measurements is influenced by the fact that the growing film finds a metallic layer instead of an oxide one, slightly modifying the growth mechanism. Pan et al. ${ }^{25}$ have observed that the oxidation of Ti foil forms brookite-rich oxides, so the formation of brookite crystallites observed in Raman and HRTEM are consistent with this observation.

The optical results clearly show an increase in the subbandgap absorption and a red-shift of the absorption edge, associated with gas flow interruption for periods longer than $40 \mathrm{~s}$. In contrast to the small changes observed in the higher energy part of the absorption edge, the changes in the absorption tails are remarkable.

Focusing on the bandgap changes determined by the higher energy range of optical measurements, a shift from $3.38 \pm 0.05 \mathrm{eV}$ to $3.14 \pm 0.05 \mathrm{eV}$ (along with a small decrease of slope) is observed as a result of the gas interruptions. The observed changes are in the same range of those occurring as a result of phase changes in $\mathrm{TiO}_{2} \cdot{ }^{10-13}$ The reported bandgaps of brookite, anatase, and rutile crystals are 3.4, 3.2, and 3.0 eV, respectively. ${ }^{10-13}$ Moreover, a decrease in the slope of the absorption edge is noticed from anatase to rutile at room temperature. ${ }^{13} \mathrm{~A}$ straightforward analysis of our optical bandgap values seems to indicate a change from brookite to anatase. Nevertheless, this is not supported by the structural or the Raman results. Therefore, it is proposed that the changes are from anatase to rutile, despite the discrepancy of the absolute values of the optical bandgaps. This discrepancy in the bandgap values could possibly be due to the higher range of the square root of the absorption coefficient used here as compared to that generally used for bulk $\mathrm{TiO}_{2},{ }^{10-12}$ 
resulting in overestimated values of the bandgaps for the present samples. In this way, there is an indication that the redshift of the bandgap and the slight decrease of the slope of the absorption coefficient versus photon energy in association with the flow interruptions are compatible with the rutile formation, since the XRD and Raman results show a tendency of increase of the rutile fraction. Nevertheless, the tendency to rutile is probably not the only reason for the optical bandgap change since the anatase phase dominates and brookite is still present in the films.

On the other hand, the enhancement of sub bandgap absorption can be associated with defects, with a clear relationship to the decrease of the oxygen concentration during deposition. In this way, oxygen-related vacancies are natural candidates for the dominating defect centers. Despite the film being a polymorph, the anatase phase dominates the structure and it is likely that the vacancies are related to this phase. In this way both the sub-bandgap absorption and part of the decrease of the bandgap are proposed to be associated with the existence of a high density of vacancies in the anatase structure. One question that arises concerning this hypothesis is if the energy levels of the oxygen-depletionrelated defects are compatible with the observed absorption.

The defect structure of this nanocrystalline columnar and polymorphic $\mathrm{TiO}_{2}$ is expected to be very complex. Furthermore, regarding the different kinds of grain boundaries and interstitials, one should consider the column interfaces and the film-substrate interface. Despite the expected high density and complexity of defects, the absorption tails of continuous gas flow films were similar to those obtained by Zallen and Moret that analyzed brookite single crystals. ${ }^{31} \mathrm{In}$ order to investigate the compatibility of the absorption enhancement with the defects produced in the films by the oxygen supply interruption, electronic structure calculations have been performed. Since the reproduction of the real complexity of the defects in the material is unattainable, a much simpler configuration of point defects (oxygen vacancies in the anatase structure) was tested.

The electronic structure of anatase with one or two adjacent vacancies, using density functional theory in the CRYSTAL09 code, places oxygen-related vacancies around $1 \mathrm{eV}$ below the bottom of the conduction band, as shown in Figs. 7 and 8. This result is in good agreement with other theoretical and experimental reports in the literature. ${ }^{32,33}$ The DOS related to the single vacancy inside the bandgap is rather localized and presents a low density of related states. In this way, the single vacancy is not a good approximation for the broad sub-bandgap optical absorption observed in Figs. 5(c) and 6-even though its energy position is compatible with the observed sub-bandgap absorption.

The double vacancy configuration used in the supercell places the two vacancies in close vicinity to each other, so strong effects of interactions between them are expected. Indeed, the resulting energy distribution of defect bandgap states is more complex, the states being distributed over a wider energy range (Fig. 6(b)). This energy distribution in the upper third of gap-state energies is compatible with the optical absorption observed at sub-bandgap energies. The DOS result for the double vacancy presents a better agree- ment with the experimental data: the electronic transitions from filled oxygen-related vacancy states to the conduction band are expected above $\sim 1 \mathrm{eV}$, and transitions from the valence band to the empty defect states existing above the Fermi level can also occur for sub-bandgap energies.

The large density of columns present in the films is associated with different kinds of interface states and is likely to be the main source of the absorption tail states observed in Fig. 6. The TEM results are similar for films deposited under continuous or interrupted gas supply.

A close analysis of the HRTEM results indicates that most of the defects are formed at the interfaces of the columns and their close vicinity. A few isolated defects can be observed in the compact columnar regions, but a large number of defects can be easily seen at the interfaces of the columns. The HRTEM images also give some indication that the interfaces between columns are more abrupt and less defective in samples deposited under continuous gas supply, as shown in Figs. 1(c) and 1(d). Even though the sample processing for TEM measurements can artificially influence the observations to some degree, it is reasonable that defects are mainly associated with column boundary regions.

It is worth noting that films grown with interruption of gas supply present a much stronger optical absorption effect than the regular films. This effect should be due to a mechanism that favors a higher defect density at the column interfaces of the interrupted flow samples in comparison to the regular flow samples. A possible mechanism that can take into account the defect density enhancement at the column interfaces during the $\mathrm{O}_{2}$ supply interruption is the partial filling of the gap between columns with Ti atoms. After the interruption, when the $\mathrm{O}_{2}$ supply is restored, it is possibly easier to oxidize the widely exposed Ti surfaces in the column tops than the less accessible deposits between columns, leaving more defects behind-especially in the column interfaces, as the film grows. Therefore, the defect density related to oxygen depletion in the interfaces of the columns is expected to be higher in films deposited with interrupted gas flow. It is also possible that a modulation of the defect density can be present in the structure. Nevertheless, it has not been possible to find evidences in the HRTEM images of this modulation along the column boundaries in samples grown using periodic interruptions of the gas flow.

In contrast to the desirable effect of enhancing the optical absorption favoring the photocatalytic activity of $\mathrm{TiO}_{2}$ by using an "intrinsic" mechanism of defect creation by periodically interrupting the $\mathrm{O}_{2}$ flux, the shortening of photo-carrier lifetime is also likely to occur. This undesirable effect can possibly be minimized by the location of the vacancies and more complex defects in the vicinity of column interfaces. As a consequence, complementary experiments are necessary to further explore the proposition to use this depleted oxygen $\mathrm{TiO}_{2}$ in photocatalysis.

The results show that it is possible to enhance the optical absorption in the visible and near infrared of $\mathrm{TiO}_{2}$ films by periodically interrupting the oxygen supply during reactive sputtering deposition. According to the present proposal, this can be accomplished by "intrinsic" means, in the sense that 
no doping impurity is necessary. Also, it is shown that the optical bandgap itself can be diminished by $0.24 \mathrm{eV}$, which can be partially due to the enhanced density of defects and to the tendency of increasing the rutile phase. These effects attributed to oxygen-related defects are essential in increasing the optical absorption at lower energies and, consequently, to improve the photocatalytic performance of $\mathrm{TiO}_{2}$.

The deposition method and the experimental results are consistent with the fact that under a 45-s interruption of the $\mathrm{O}_{2}$ gas supply the oxidation of the Ti-rich deposit is partial, leaving behind defects (essentially oxygen-related vacancies) that become apparent in the absorption spectrum. The interruption of $\mathrm{O}_{2}$ during deposition, associated with the high reactivity of the oxygen species in the plasma, can be used to control the introduction of defects in $\mathrm{TiO}_{2}$ films deposited by sputtering. In fact, the present investigation shows that the methodical supply of $\mathrm{O}_{2}$ gas during deposition by sputtering produces better control of the density of defects in $\mathrm{TiO}_{2}$.

Even though the red shift of the absorption edge observed here is smaller than that reported on extrinsically doped $\mathrm{TiO}_{2}$ films, ${ }^{3,34-36}$ the decrease in transmittance at subbandgap energy is significant. This suggests that a combination of extrinsic doping and $\mathrm{O}_{2}$ gas supply interruption can be used to produce films with optimized photocatalysis efficiency.

\section{CONCLUDING REMARKS}

$\mathrm{TiO}_{2}$ films with enhanced visible and near-infrared optical absorption tails have been produced by periodically interrupting the $\mathrm{O}_{2}$ gas flow in the reactive plasma during RF magnetron sputtering deposition. A sudden change in the sub bandgap absorption of the films with the duration of the interruptions was observed and associated to the delay necessary for the effective depletion of the oxygen species in the plasma.

The XRD, HRTEM, and Raman scattering measurements show that the films have a compact columnar morphology and consist of anatase, rutile, and brookite phases. HRTEM analysis could not detect significant morphology and composition changes along the growing axis of the films; instead, the observed changes at the column interface regions suggest that the modifications occur at the column interfaces. The results show that intrinsic modifications through defects produced by oxygen depletion in the films can produce the large effects observed in the optical absorption tails without significantly changing the structure of the $\mathrm{TiO}_{2}$ films. The corresponding optical absorption spectra are consistent with defect-induced absorption. In particular, DFT calculations place oxygen-related vacancy states $\sim 1 \mathrm{eV}$ below the bottom of the conduction band and fit the observed absorption when two vacancies are placed close to each other. It is proposed that the defects related to the oxygen deficiency are produced during growth by the partial oxidation of the Ti-rich deposits formed during the gas supply interruption. As a result, the density of defects can be controlled by adjusting the interruption time and the period between interruptions.

The results are potentially important concerning the applications of $\mathrm{TiO}_{2}$ films, with special mention to photoca- talysis processes and regarding the magnetic properties of $\mathrm{TiO}_{2}$ in association with defects and/or doping with transition metals.

\section{ACKNOWLEDGMENTS}

The authors acknowledge the LCME and LDRX laboratories of the Universidade Federal de Santa Catarina for the use of the TEM and XRD facilities. This work was supported in Brazil by Fapesp (Grants 2007/08072-0 and 2008/104304) and in Spain by Fundación Carolina (Grant 3939-10-3).

${ }^{1}$ A. Fujishima, X. Zhang, and D. A. Tryk, Surf. Sci. Rep. 63, 515 (2008). ${ }^{2}$ W.-J. Jeong, I.-S. Moon, S.-K. Cho1, H.-H. Yang, G.-C. Park, H.-B. Gu, K.-J. Kim, and H.-G. Ahn, J. Nanosci. Nanotechnol. 11, 1565 (2011). ${ }^{3}$ L. Wan, J. F. Li, J. Y. Feng, W. Sun, and Z. Q. Mao, Appl. Surf. Sci. 253, 4764 (2007).

${ }^{4}$ S. A. Chambers, Surf. Sci. Rep. 61, 345 (2006).

5 J. M. D. Coey, P. Stamenov, R. D. Gunning, M. Venkatesan, and K. Paul, New J. Phys. 12, 053025 (2010).

${ }^{6}$ U. Diebold, Surf. Sci. Rep. 48, 53 (2008).

${ }^{7}$ S. Mráz and J. M. Schneider, J. Appl. Phys. 109, 023512 (2011).

${ }^{8}$ J. A. Thornton, J. Vac. Sci. Technol. A 4, 3059 (1986).

${ }^{9}$ J. I. Cisneros, Appl. Opt. 37, 5262 (1998).

${ }^{10}$ W. Hu, L. Li, G. Li, C. Tang, and L. Sun, Cryst. Growth Des. 9, 3676 (2009).

${ }^{11}$ M. Koelsch, S. Cassaignon, J. F. Guillemoles, and J. P. Jolivet, Thin Solid Films 403-404, 312 (2002).

${ }^{12}$ H. Tang, K. Prasad, R. Sanjinès, P. E. Schmid, and F. Lévy, J. Appl. Phys. 75, 2042 (1994).

${ }^{13}$ H. Tang, F. Lévy, H. Berger, and P. E. Schmid, Phys. Rev. B 52, 7771 (1995).

${ }^{14}$ R. Dovesi, V. R. Saunders, C. Roetti, R. Orlando, C. M. Zicovich-Wilson, F. Pascale, B. Civalleri, K. Doll, N. M. Harrison, I. J. Bush, P. D’Arco, and M. Llunell, CRYSTAL09 User's Manual, Torino, 2009, see http:// www.crystal.unito.it.

${ }^{15}$ R. A. Evarestov, Quantum Chemistry of Solids: The LCAO First Principles Treatment of Crystals (Springer-Verlag, 2007), Vol. 153.

${ }^{16}$ A. D. Becke, J. Chem. Phys. 98, 5648 (1993).

${ }^{17}$ C. T. Lee, W. T. Yang, and R. G. Parr, Phys. Rev. B 37, 785 (1988).

${ }^{18}$ V. A. Rassolov, J. A. Pople, M. A. Ratner, and T. L. Windus, J. Chem. Phys. 109, 1223 (1998).

${ }^{19}$ A. Beltran, J. R. Sambrano, M. Calatayud, F. R. Sensato, and J. Andres, Surf. Sci. 490, 116 (2001).

${ }^{20}$ S. Grimme, J. Comput. Chem. 27, 1787 (2006).

${ }^{21}$ T. Bucko, J. Hafner, S. Lebegue, and J. G. Angyan, J. Phys. Chem. A 114, 11814 (2010)

${ }^{22}$ D. L. Smith, Thin Film Deposition: Principles and Practice (McGraw Hill, Boston, 1995), $616 \mathrm{p}$.

${ }^{23}$ C. R. Aita, Appl. Phys. Lett. 90, 213112 (2007).

${ }^{24}$ M. P. Moret, R. Zallen, D. P. Vijay, and S. B. Desu, Thin Solid Films 366, 8-10 (2000).

${ }^{25}$ H. Pan, X. Qiu, I. N. Ivanov, H. M. Meyer, W. Wang, W. Zhu, M. P. Paranthaman, Z. Zhang, G. Eres, and B. Gu, Appl. Catal., B 93, 90-95 (2009)

${ }^{26}$ A. Di Paola, M. Addamo, M. Bellardita, E. Cazzanelli, and L. Palmisano, Thin Solid Films 515, 3527 (2007).

${ }^{27}$ G. A. Tompsett, G. A. Bowmaker, R. P. Cooney, J. B. Metson, K. A. Rodgers, and J. M. Seakins, J. Raman Spectrosc. 26, 57-62 (1995).

${ }^{28}$ K. Meyer, I. K. Schuller, and C. M. Falco, J. Appl. Phys. 52, 5803 (1981).

${ }^{29}$ K. Okimura and A. Shibata, Jpn. J. Appl. Phys., Part 1 36, 313 (1997).

${ }^{30}$ L. Miao, P. Jin, K. Kaneko, A. Terai, N. Nabatova-Gabain, and S. Tanemura, Appl. Surf. Sci. 212-213, 255 (2003).

${ }^{31}$ R. Zallen and M. P. Moret, Solid State Commun. 137, 154 (2006).

${ }^{32}$ T. V. Perevalov and V. A. Gritsenko, J. Exp. Theor. Phys. 112, 310 (2011).

${ }^{33}$ A. Beltrán, L. Gracia, and J. Andrés, J. Phys. Chem. B 110, 23417 (2006).

${ }^{34}$ A. Nakaruk, C. Y. W. Lin, D. Channei, P. Koshy, and C. C. Sorrell, J Sol-Gel Sci. Technol. 61, 175 (2012).

${ }^{35}$ A. Hajjaji, M. Gaidia, B. Bessais, and M. A. El Khakani, Appl. Surf. Sci. 257, 10351 (2011).

${ }^{36}$ B. Santara, B. Pal, and P. K. Giri, J. Appl. Phys. 110, 114322 (2011). 